Revista Aspas

ppgac - USP

Forma Livre

\title{
ARQUITETURAS DO CORPO E INTERVENÇÃO URBANA: NOTAS SOBRE A CONTRIBUIÇÃO DE MARCELO DENNY
}

Arianne Vitale Cardoso, Carol Pinzan, Christiane Martins, Francisco Dal Col, Igor Martins, Letícia Coura, Marcelo Prudente, Marie Auip, Renato Bolelli Rebouças, Renato Navarro e Rodrigo Severo, membros do LPP, em parceria e sob orientação de Marcos Bulhões Martins.

Arianne Vitale Cardoso, Carol Pinzan, Christiane Martins, Francisco Dal Col, Igor Martins, Letícia Coura, Marcelo Prudente, Marie Auip, Renato Bolelli Rebouças, Renato Navarro e Rodrigo Severo, membros do LPP, em parceria e sob orientação de Marcos Bulhões Martins. 
Qual é o lugar do corpo nas artes performativas? Como o corpo é expandido, recriado e simbolizado? Como criar formas poéticas de presentificação do corpo em suas diferentes possibilidades? Esses questionamentos refletem as ações artísticas do Laboratório de Práticas Performativas (LPP) da USP, onde Marcelo Denny teceu uma espécie de panorama das Arquiteturas do Corpo, descritas por ele como diretrizes de análise das artes performativas sob o viés do corpo, que se expande através de construções, visualidades, pinturas, ornamentos, próteses, aparatos relacionais, rituais e tecnológicos (LEITE, 2019).

Ao identificar uma "intensificação de fusões, associações, misturas, que acabam por borrar os limites e retemperar princípios, expandindo possibilidades e projetando novas formas de fazer, saber e ver" ${ }^{1}$, esta compreensão dos corpos contemporâneos atravessados por diferentes questões "possibilita o surgimento de novos territórios bem como requer um novo instrumental teórico para lidar com um hibridismo sem fim que percebe a arte hoje como um dinâmico e caótico caleidoscópio"2, afirma o pesquisador. Organizadas como categorias proeminentes nas artes performativas a partir do século XX - Corpo Sagrado, Corpo Ritual, Corpo Social, Corpo Expandido, Corpo Relacional, Corpo Artivista e Corpo Tecnológico - estas arquiteturas refletem diferentes qualidades que constroem campos sensíveis de expressão a partir das afetações do corpo no campo da arte. "Entre objeto e presença, entre corpo e sujeito, entre corpo e metáfora, essas arquiteturas evocam e ampliam a dimensão corpórea, bem como a sua comunicação."

Para Denny, o conceito de arquiteturas compreende desde as antigas formas de constructos corporais, numa dimensão sagrada ancestral, recuperando a figura do xamã - termo que significa, em termos gerais, "aquele que vê além", "pajé, bruxo, feiticeiro ou mago"4, podendo ser designado como

\footnotetext{
1 Ibid., p. 49.

${ }^{2}$ Ibid., op. cit.

${ }^{3}$ Ibid., p. 34.

${ }^{4}$ Ibid., p. 09.
} 
o performer do corpo (proto-teatro) ${ }^{5}$ - até as produções contemporâneas de diferentes origens que investem na potência do corpo a partir de novas tecnologias relacionais. Em geral, essas construções se tornam "materializações de aspectos invisíveis, obscuros, psicológicos, mentais, espirituais do ser humano, como uma espécie de tradução da materialidade no corpo em aspectos abstratos, sensações, crenças e outros processos imperceptíveis na vida, que se configuram como uma constelação de signos e texturas". 6

Denny, no artigo escrito em parceria com FREITAS (2020), analisa que o "papel duplo do artista, tanto de sujeito quanto de objeto, acabou com a fronteira entre ele e o espectador, bem como entre criação e recepção".7 Nestes processos, o corpo metamorfoseado passa a atuar em "narrativas anteriormente reprimidas como, por exemplo, as da sexualidade, dos fluídos e das morfologias, ou seja, na dimensão da diferença", ${ }^{8}$ em composições com forte identificação em sua mitologia pessoal, que articulam diferentes temas, marcas e conflitos na produção de subjetividade.

Assim, as práticas performativas congregam uma "multiplicidade ou mesmo uma mestiçagem de perspectivas", que se articulam de modos diversos. Ainda segundo Denny, o termo "mestiçagem em arte se endereça melhor às produções das artes do corpo, em especial nos tempos atuais, em que as novas geografias, miscigenações, nomadismos e ligações entre culturas, línguas, tecnologias globalizadas interagem no tempo hiperconectado", onde o corpo, ao se abrir para campos expandidos, "refaz sua força e possibilita ser uma plataforma para apontar para nossas incompletudes". 9

\footnotetext{
${ }^{5}$ Segundo Denny, "O xamã anuncia e incorpora divindades em seu corpo na forma de construções corporais, responsáveis através dele por religar os planos terreno e sagrado de seu povo fazendo uso desses acessórios, através de uma série de ritos, sempre com base no seu corpo e no corpo coletivo do seu grupo." Ibid. p. 09.

${ }^{6}$ Ibid., p. 11.

${ }^{7}$ FREITAS, Eduardo Bruno Fernandes Freitas e LEITE, Marcelo Denny de Toledo Leite. Provocações possíveis para perguntas infindáveis: corpo, arte e pandemia. Rebento, São Paulo, n. 12, p. 269279, jan - jun 2020, p. 275.

${ }^{8}$ Ibid., op. cit.

${ }^{9}$ LEITE, op. cit., p. 61.
} 
É essa abordagem do corpo e suas potências nas artes, que fundamentam o termo Arquiteturas do Corpo elaborado por Denny constitui um dos pontos de intersecção do LPP, refletido nas pesquisas resultantes das disciplinas e práticas dentro e fora da Universidade. Suas elaborações conceituais em torno do corpo performativo geraram reflexões e resultados estéticos produzidos em colaboração com alunes e parceires, incluindo também 0 debate sobre a pedagogia da Arte da Performance. Os desdobramentos desta pesquisa têm sido investigados por outros pesquisadores, dando continuidade aos estímulos provocados pelo artistapesquisador que nos deixou um legado fundamental sobre o ensino, a história da arte da performance brasileira.
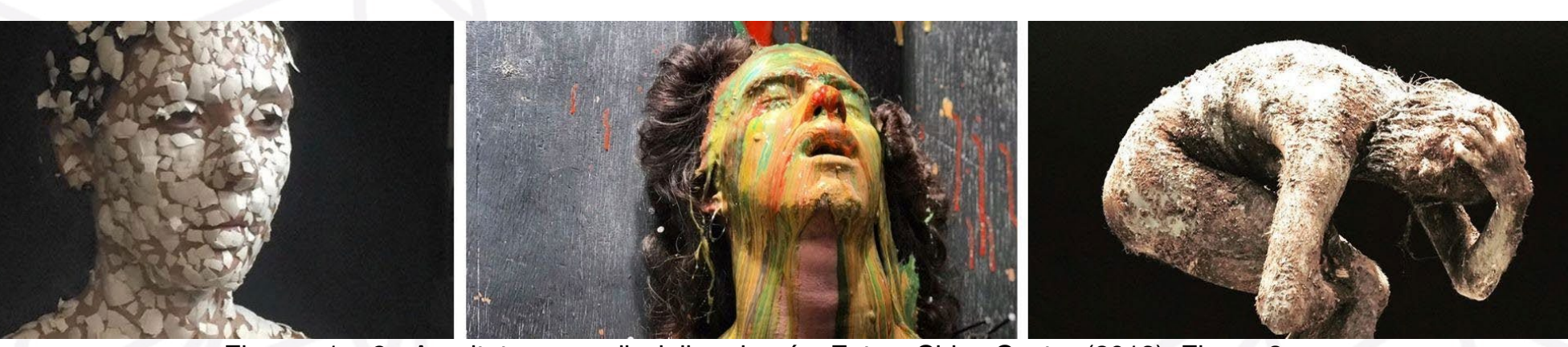

Figuras 1 e 2 - Arquiteturas na disciplina da pós. Fotos: Chico Castro (2018). Figura 3 Arquiteturas na graduação. Foto: Chico Castro (2018).

\section{Arquiteturas do corpo no espaço urbano}

Ao longo de sua trajetória iniciada no final dos anos 1990, Marcelo Denny colaborou como diretor artístico e também como fundador de coletivos de teatro e performance, com os quais explorou diferentes possibilidades de Arquiteturas do Corpo. Em Pindamonhangaba (SP), dirigiu a Cia. Cadê Otelo, que circulou em diversos festivais do país com o espetáculo "A Barca do Inferno", que se inciava com uma viagem de trem até uma olaria situada fora da cidade, onde o público se confrontava com a dramaturgia de imagens oníricas ampliadas pela presença de corpos expandidos por próteses, pinturas, adereços e mascaramentos. 
Denny atuou como diretor de arte, provocador, cenógrafo, co-criador, em diferentes contextos: encenações de temática LGBTQIA+, de Marcelo Braga, as experimentações na rua Augusta dirigidas por Evil Rebouças, a intervenção urbana "Corpos Pintados" do Coletivo URUBUS, na qual Denny pintava o corpo desnudo de mulheres que iriam intervir ruas e equipamentos públicos no centro de Sao Paulo. Denny coloborou na gênese do Coletivo Marimbondo de Performance em Natal (RN), quando foi diretor de arte do acontecimento cênico "Devorando Fausto", utilizando a Fortaleza dos Reis Magos como suporte de imagens em vídeo.

Denny manteve ainda parceria constante com dois grupos, a Cia. Sílvia Que Te Ama Tanto, em Bauru (SP), e Cia. do Trailler de São José dos Campos (SP). Nos últimos dois anos, foi diretor de arte e provocador dos espetáculos "Sutil Violento" e "(In)justiça" da Companhia de Teatro Heliópolis. Fundou e participou como um dos diretores artísticos de dois coleivos em São Paulo que surgiram através de cursos do Laboratório: Teatro da Pomba Gira ${ }^{10}$ e Desvio Coletivo ${ }^{11}$. A seguir, enfocaremos intervenções urbanas nas quais as formas de inventividade e o ponto de vista crítico de Marcelo Denny foram determinantes.

A performance "Cegos", concebida por Denny e Bulhões, se apresenta como um coro de executivos vestidos em traje social, cobertos de argila e com os olhos vendados, caminhando lentamente no fluxo urbano. A disposição da obra em dialogar com o espaço citadino possibilitou a participação, através de oficinas, de pessoas interessadas em integrar o coro performativo. A concepção original e seu processo de feitura foram redimensionados e ampliados a partir da circulação do Desvio Coletivo por diferentes cidades distribuídas por quatro continentes ${ }^{12}$, envolvendo mais de 1000 participantes.

\footnotetext{
${ }^{10}$ www.teatrodapombagira.art

${ }^{11}$ www.desviocoletivo.com.br

${ }^{12}$ A performance conquistou prêmios nacionais como o Funarte de Teatro Myriam Muniz (2015) e o Palco Giratório do Sesc (2014), circulando pela grande maioria dos estados brasileiros, tendo sido selecionada para eventos internacionais na República Tcheca, Costa Rica, Portugal, Suíça, Taiwan, Cabo Verde, Coréia do Sul, França, Malásia e Bélgica. As apresentações em Paris, Barcelona, Nova York e Amsterdã deram-se através do edital da Pró-Reitoria de Cultura e Extensão da USP (2013) e da parceria com importantes instituições acadêmicas como o Hemisferic Institute of Performance
} 
Arianne Vitale Cardoso, Carol Pinzan, Christiane Martins, Francisco Dal Col, Igor Martins, Letícia Coura, Marcelo Prudente, Marie Auip, Renato Bolelli Rebouças, Renato Navarro e Rodrigo Severo, em parceria e sob orientação de Marcos Bulhões Martins.
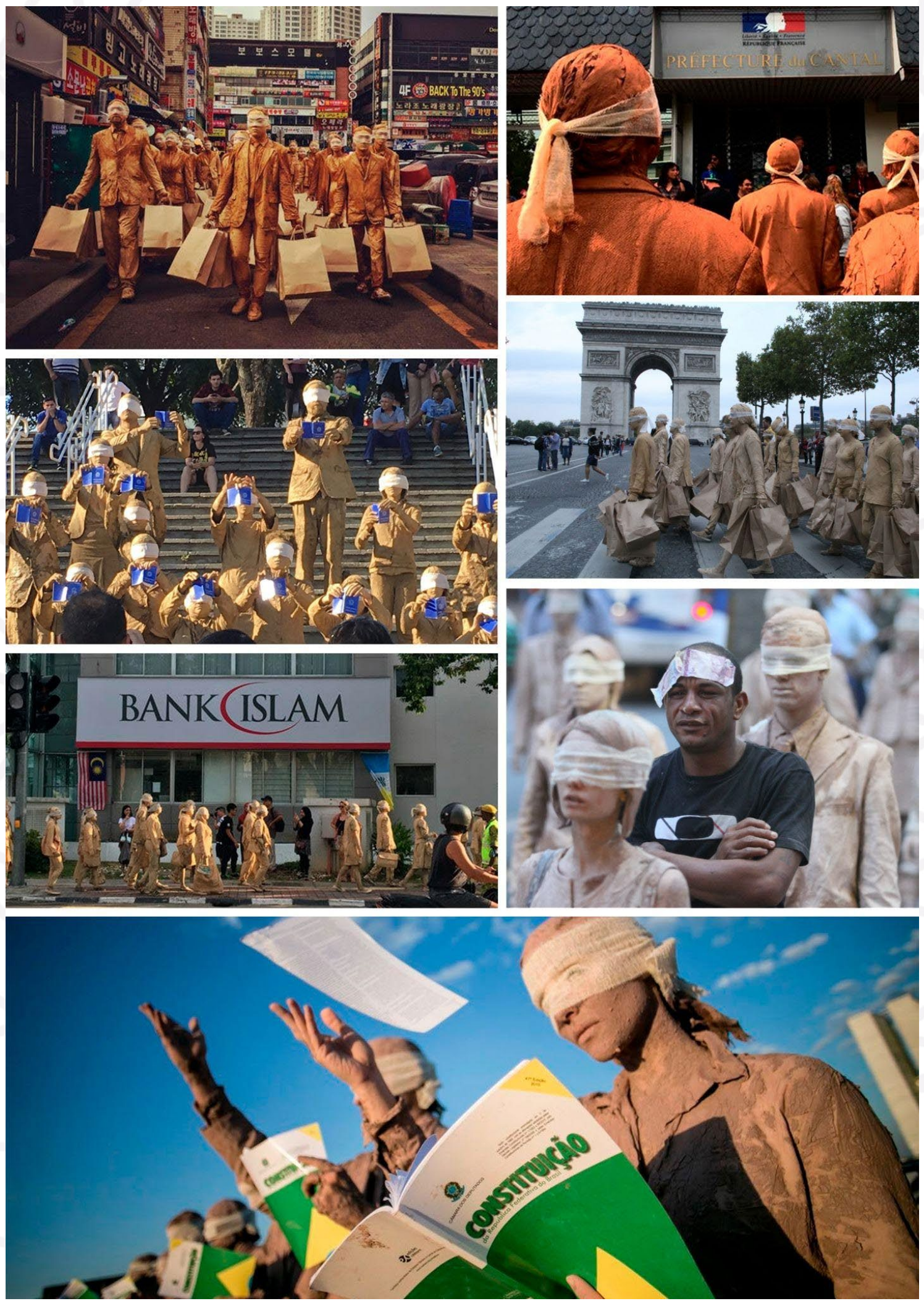

and Politics da NYU, que, além de Cegos co-produziu a performance antifacista Banho de Descarrego (2019) em Nova York (https://hemisphericinstitute.org/pt/events/banho-dedescarrego-an-anti-fascist-performance.htm). 
No período de quase uma década, as ações foram sendo construídas a partir de um dispositivo de dramaturgia relacional, sendo uma plataforma de discussão sobre o formato da obra adotada em cada localidade, no qual cada ponto em relação ao trajeto ${ }^{13}$ e os gestos ${ }^{14}$ passaram a ser decididos de forma coletiva, criando uma rede entre os imaginários dos integrantes do Desvio Coletivo e dos moradores locais. Cada performer pode ser visto como sujeito de uma coralidade sensível ao que ocorre em sua volta, onde as conexões se multiplicam, logo, a intensidade também, e disso surge a potencialidade da ação de ser lida através de identificações com o corpo social do local onde se apresenta, como uma ação disruptiva e reflexiva.

Marcelo Denny e Eduardo Bruno, no artigo Confrontos Poéticos e Políticos: o corpo e a cidade na performance urbana "Cegos" (2015), sintetizaram bem uma das principais características de "Cegos" ao considerarem a obra como sendo uma

[...] arte de fronteira que borra a hierarquia arte e vida. Alterando tanto os corpos participantes (performers), pois na realização de tal trabalho, os performers modificam seus ritmos corporais que cotidianamente são mecanizados, quanto o dos passantes (público) que são confrontados com corpos que de modo expandido e poético são imagem de nossos corpos dóceis e sociais. ${ }^{15}$

Dando sequência à pesquisa de coralidades urbanas do Desvio Coletivo, "Matrimônios" surge como proposta de intervenção urbana que traz questionamentos sobre o modelo cis-heteronormativo e monogâmico das relações. A partir da imagem de um coro de noivos e noivas que celebram o amor em todas as suas possibilidades, percorrendo o espaço público

\footnotetext{
${ }^{13} \mathrm{Em}$ cada cidade, o trajeto que o coro de performers percorre durante a ação é construído através de uma cartografia dos prédios que simbolizam instituições de poder religioso, financeiro, judiciário e político.

${ }^{14}$ Os gestos são incluídos durante todo o trajeto e dialogam com as instituições através de processos de valorização, avaliação ou conflito. Exemplo: Realizar uma saudação religiosa em frente à uma instituição bancária ou mostrar as mãos pintadas de vermelho em frente a estátuas que simbolizam violência.

${ }^{15}$ BRUNO, Eduardo; DENNY, Marcelo. Confrontos Poéticos e Políticos: o corpo e a cidade na performance urbana "cegos". In: Arte e política : IV Diálogos Internacionais em Artes Visuais e I Encontro Regional da ANPAP/NE. Programa Associado de Pós-graduação em Artes Visuais UFPB/UFPE. Recife : Editora UFPE, 2015. p. 387-392. p. 391.
} 
tomando-o como altar, propõe-se "refletir sobre a igualdade e multiplicidade de gêneros através do estranhamento poético da imagem clássica do casamento cristão". ${ }^{16}$ Ao instaurar imagens cênicas que subvertem o modelo tradicional de casamento, o coro instaura uma abertura de frestas na percepção do público, possibilitando a existência de uma zona de enfrentamento, alargando a noção de união estável amorosa.

Em "Cegos" e "Matrimônios", a relação entre arte e ativismo radicalizouse na trajetória do grupo, principalmente a partir da ascensão dos movimentos de extrema direita desde as jornadas de junho de 2013. Nesse sentido, novas ações artísticas denominadas coralidades performativas artivistas foram desenvolvidas, tais como "Interditados"17, que ocorreu em dezembro de 2015 a partir de uma vivência de sete dias do LPP com estudantes da Escola Estadual Maria José, e que resultou em uma ação performativa na Av. Paulista (São Paulo) como resposta cênica ao momento político vivido pelos estudantes secundaristas do Estado de São Paulo que ocuparam os prédios de suas escolas em busca de melhorias ao Sistema Estadual de Ensino Público; e "Máfia", realizada em 2016, em resposta imediata à votação do impeachment na câmara dos deputados.

A ação artística expressava o repúdio aos deputados federais que votaram a favor do impedimento da presidenta Dilma Rousseff e que tinham seus nomes vinculados a processos criminais. Como se fossem obras expostas no museu, o grupo fixou no vão do Masp fotos de alguns destes políticos junto a uma lista de crimes dos quais eram acusados. Sentados em frente às imagens, os performers cuspiam nas fotografias, tomando como mote o cuspe de Jean Willys no então deputado Jair Bolsonaro, como reação à homenagem prestada ao torturador Coronel Ustra. A ação foi se intensificando a partir da participação e incitação dos transeuntes, que também se mostraram incomodados com o acontecimento político. A performer Priscilla Toscano concluiu a ação urinando e defecando na

\footnotetext{
${ }^{16}$ MARTINS, 2018, p. 365.

17 Todo o processo disponível em: https://ariannevitale.blog/performance/projeto-acumulo/
} 
fotografia de Jair Bolsonaro, ato que gerou uma grande polêmica e ameaças de morte e perseguição na internet de militantes fascistas que, para a pesquisadora Alessandra Montagner (2018), atestou "o poder de contágio inerente à performance que é relacionado às suas dimensões estéticas, éticas e políticas". ${ }^{18}$
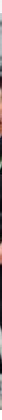

Figura 19 - Interditados. Foto: Bruno Santos/Folhapress (2015). Figura 20 - Máfia. Foto:

Acervo Desvio Coletivo (2016). Figura 21 - Matrimônios. Foto: Amanda Vicentini (2018).

A ação de coralidade artivista, urbana e participativa mais recente desenvolvida pelo LPP, foi "Banho de Descarrego" ${ }^{19}$, de Denny e Bulhões, produzida pela Associação de Pesquisa em Artes Cênicas (ABRACE) em Natal em 2018, e pelo Hemisferic Institut de Performance and Politcs, em Nova lorque, em 2019. Trata-se de uma instalação em espaço público qual uma lavagem pública de corpos pintados cobertos por suásticas, realizada pelos espectadores transeuntes, encena a erradicação de ideologias autoritárias e fundadas no ódio. A ação critica o neofascismo contemporâneo, representado por ideias e ações autoritárias defendidas por Donald Trump, Jair Bolsonaro e outros governantes nos últimos anos, utilizando a suástica como símbolo universal de opressão.

\footnotetext{
${ }^{18}$ MONTAGNER, Alessandra. Corpos despedaçados: choque e espectação nas artes da cena. 2018. Tese (Doutorado em Artes da Cena) - Instituto de Artes, Universidade Estadual de Campinas, Campinas, 2018.

${ }^{19}$ Para mais sobre Banho de Descarrego em Natal/RN, ver <https://fb.watch/7Po5RA08PF/>. Acesso em: 04 set. 2021.Para mais sobre Banho de Descarrego em Nova York, ver $<$ https://hemisphericinstitute.org/pt/events/banho-de-descarrego-an-anti-fascistperformance.htm > Acesso em: 04 set. 2021.
} 

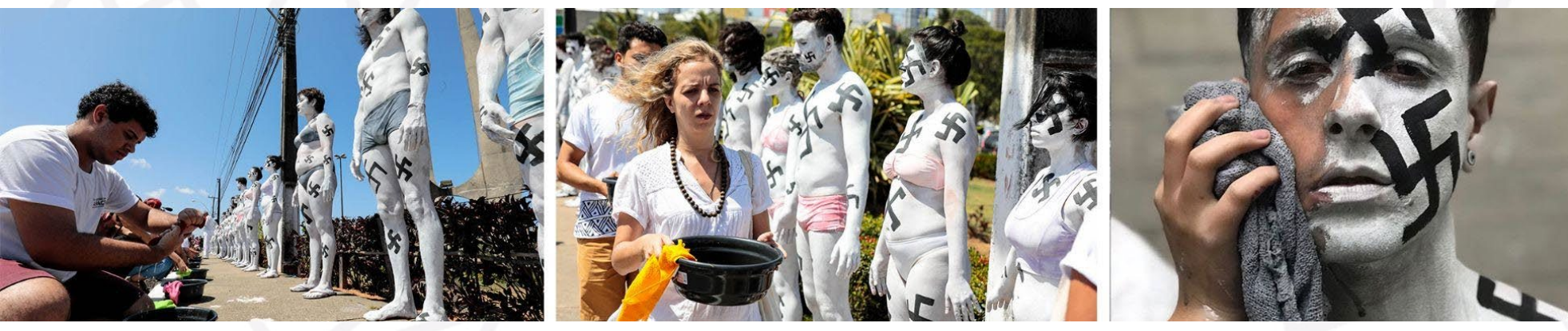

Através da intersecção entre performance, arte participativa, intervenção no espaço urbano e artivismo, as arquiteturas corporais e as ações disruptivas das coralidades performativas urbanas, desenvolvidas sob a influência criativa de Marcelo Denny, geraram ilhas de desordem poética e crítica através de provocações significativas no tecido social brasileiro.

\section{ECOS DE UMA POTÊNCIA DE VIDA: REVERBERAÇÕES, RESSONÂNCIAS E EXPANSÕES}

Concluímos este texto na data que marca um ano da partida de Marcelo Denny. Sua presença continua reverberando nas ações artísticas e acadêmicas aqui abordadas e inspirando-nos com sua potência de vida. Em seu desejo por "assanhar inquietações" estéticas, filosóficas, corporais, pedagógicas, comportamentais, Denny fez de sua vida uma incubadora de experimentos e alimento para o desenvolvimento de sua arte e de muitas outras pesquisas. Seu trabalho ressoa nas abordagens radicais em muitas dimensões, como professor, artista, pesquisador e, também, como amigo da maioria das pessoas que aqui se uniram para essa escrita coletiva. Uma escrita que constitui um rito de passagem, onde exaltamos a corporeidade implicada nas relações entre pesquisa acadêmica e artística, conectando e expandindo esta rede de ações que se multiplicam. Deste modo, afirmamos uma práxis cuja teoria é desenvolvida a partir da experiência, onde o processo 
criativo atualiza o próprio conceito investigado, num percurso contínuo e compartilhado.

"Novas percepções, processos compartilhados e potências na performance contemporânea" foi o subtítulo da última pesquisa de Denny e traduz o seu legado junto ao LPP. Os interesses de Denny expandiram-se em direções complementares, resultando na publicação de dois livros - Gênero expandido: performances e contrassexualidades (2018), organizado com Dodi Leal, e Cenografia Digital na Cena Contemporânea (2019), resultado de seu doutorado, que trazem contribuições fundamentais para o estudo das práticas performativas. Para além do teatro e da performance, Marcelo Denny expandiu também sua prática ao audiovisual, resultando em diversos projetos e colaborações como diretor de arte, roteirista e diretor, com destaque para o curta-metragem "Pele Digital".

O Laboratório, ao articular pesquisas e práticas que se desdobram em artivismo e cartografias, segue expandindo e ampliando as relações entre as Artes Cênicas e performativas em diálogo com os cenários sócio-políticos de cada momento. Um percurso que poliniza formas coletivas de criação e transmutação e se abre ao que poderá surgir das mais diversas respostas aos estímulos pulsantes do "corpo-obra em arte-vida" 20 Seguimos. Denny presente!

\section{REFERÊNCIAS}

FREITAS, Eduardo B F. e LEITE, Marcelo Denny de Toledo. Provocações possíveis para perguntas infindáveis: corpo, arte e pandemia. Rebento, São Paulo, n. 12, jan-jun 2020.

FREITAS, Eduardo B. F. e LEITE, Marcelo Denny de Toledo. Confrontos Poéticos e Políticos: o corpo e a cidade na performance urbana "cegos". IN: Arte e política: IV Diálogos Internacionais em Artes Visuais e I Encontro Regional da ANPAP/NE. Programa de Pós-graduação em Artes Visuais UFPB/UFPE. Recife: Editora UFPE, 2015. P. 387-392

${ }^{20}$ LEITE, op. cit, p. 0.2. 
LEITE, Marcelo Denny de Toledo. Arquiteturas do corpo: Novas percepções, processos compartilhados e potências na performance contemporânea.

Relatório de pesquisa de pós-doutorado. Rio de Janeiro: Unirio, 2019.

LEITE, Marcelo Denny de Toledo. Cenografia Digital na cena contemporânea.

São Paulo: Annablume, 2019.

LEAL, Dodi; LEITE, Marcelo Denny de Toledo (Org.). Gênero expandido:

performances e contrassexualidades. São Paulo: Annablume, 2018..

MARTINS, Marcos Aurélio Bulhões. Coralidades Performativas e subversão da cisheteronormatividade: teatro e performance na expansão de gênero, sexualidade e afetividade. In: LEAL, Dodi; LEITE, M. D. T. (Org.). Gênero expandido:

performances e contrassexualidades. São Paulo: Annablume, 2018, p. 343-376. MONTAGNER, Alessandra. Corpos despedaçados: choque e espectação nas artes da cena. 2018. Tese (Doutorado em Artes da Cena). Instituto de Artes, Universidade Estadual de Campinas, Campinas, 2018 